\title{
Urethritis Cystica
}

National Cancer Institute

\section{Source}

National Cancer Institute. Urethritis Cystica. NCI Thesaurus. Code C96225.

A reactive inflammatory disorder affecting the urethra. It is characterized by the development of small cysts in the urethral wall. The cysts are lined by urothelial cells. 